\title{
Psychopharmacology of Aversively \\ Motivated Behavior
}


Hymie Anisman

Department of Psychology

Carleton University

Ottawa, Ontario, Canada

Herbert Barry, III

Department of Pharmacology

School of Pharmacy, University of Pittsburgh

Pittsburgh, Pennsylvania

Giorgio Bignami

Laboratorio di Farmacologia

Istituto Superiore di Sanità

Roma, Italy

Hanna Michałek Laboratorio di Farmacologia

Istituto Superiore di Sanità

Roma, Italy

Bruce A. Pappas

Department of Psychology

Carleton University

Ottawa, Ontario, Canada

David A. V. Peters Department of Pharmacology

University of Ottawa

Ottawa, Ontario, Canada

Richard H. Rech Department of Pharmacology

Michigan State University

East Lansing, Michigan

$\begin{array}{ll}\text { Alvin K. Swonger } & \begin{array}{l}\text { Department of Pharmacology and Toxicology } \\ \text { College of Pharmacy, University of Rhode Island } \\ \text { Kingston, Rhode Island }\end{array} \\ \text { Douglas Wahlsten } & \begin{array}{l}\text { Department of Psychology } \\ \text { University of Waterloo } \\ \text { Waterloo, Ontario, Canada }\end{array}\end{array}$ 


\section{Psychopharmacology of Aversively Motivated Behavior}

Edited by

Hymie Anisman

Carleton University

Ottawa, Ontario, Canada

and

Giorgio Bignami

Istituto Superiore di Sanità

Rome, Italy 


\section{Library of Congress Cataloging in Publication Data}

Main entry under title:

Psychopharmacology of aversively motivated behavior.

Includes bibliographies and indexes.

1. Psychopharmacology. 2. Brain chemistry. 3. Neuropsychopharmacology. 4. Avoidance (Psychology) I. Anisman, Hymie. II. Bignami, Giorgio. [DNLM: 1. Avoidance learning 2. Psychopharmacology. 3. Behavior-Drug effects. 4. Motivation. 5. Psychotropic drugs-Pharmacodynamics. QV77 P9727]

(c) 1978 Plenum Press, New York

Softcover reprint of the hardcover 1st edition 1978

A Division of Plenum Publishing Corporation

227 West 17th Street, New York, N.Y. 10011

All rights reserved

No part of this book may be reproduced, stored in a retrieval system, or transmitted, in any form or by any means, electronic, mechanical, photocopying, microfilming, recording, or otherwise, without written permission from the Publisher 


\section{Preface}

During the past two decades, remarkable advances have been made in psychopharmacology, resulting in increased demands for journal space (witness the large number of journals that cater primarily or exclusively to this topic). Concomitantly, a need developed for more integration of the currently available data. To this end, numerous edited volumes in psychopharmacology have appeared which have been primarily concerned with the role of a particular drug or system in modulating a wide variety of behaviors. While such texts have been most useful in elucidating drug mechanisms and the etiology of a number of behaviors, few attempts have been made to evaluate and integrate pharmacological treatments within a single behavioral category. Specifically, the researcher interested in understanding a given behavior from a neurochemical point of view must consult several texts, each dealing with a different chemical or system. When texts are obtained covering a broad spectrum of systems, they also invariably deal with many different behaviors, thus not allowing for complete integration within a behavioral category. The present volume was planned to meet the needs of the scientist interested in understanding neurochemical mechanisms underlying aversively motivated behavior, as well as drug effects thereon.

In organizing the contents of this text, it quickly became apparent that any attempt to provide a complete overview of behavioral and pharmacological information pertaining to aversive situations was not practical for at least two reasons. First, a considerable portion of this information belongs in highly specialized texts on behavioral endocrinology, macromolecular events in behavioral regulation, and specific learning phenomena, such as memory consolidation. In fact, excellent reviews and books are currently available concerning hormone effects on aver- 
sively motivated behaviors, changes in acquisition and retention induced by chemicals that modify protein and nucleic acid metabolism, and agents, mainly convulsants, which have been widely employed in the analysis of memory consolidation. Clearly, any attempt to explore these areas would have led to a multivolume enterprise, much of which inevitably would prove to be redundant with recerit reviews. Accordingly, the content of the book was restricted to those areas evaluated extensively but not available in a compact integrated form. The reader will find the initial chapter summarizing the organization of aversively motivated behavior and methodological issues in treatment evaluation. This is followed by a chapter analyzing genotype $\times$ environment interactions that are relevant for the understanding of learning, in general, and avoidance performance, in particular. Chapter 3 describes the neurochemical consequences of stress and the necessary and sufficient conditions in order that these changes occur. Chapters 4 and 5 assess the effects of cholinergic and monoaminergic treatments, respectively, in a variety of aversive paradigms, cutting through several levels of organization-physiological, biochemical, and behavioral. The two following chapters necessarily use a less unitary approach, since they cover heterogeneous groups of agents. Specifically, Chapter 6 considers hallucinogens belonging to different chemical classes, whereas Chapter 7 concentrates on a broad list of psychotropic drug groups that have little in common with each other. Stimulus attributes of drugs, which have become essential in any psychopharmacological analysis, are reviewed in Chapter 8 . Finally, the closing chapter represents a tentative overview of the current state of affairs pertaining to the pharmacologic analysis of aversively motivated behaviors.

Last, but certainly not least, we wish to acknowledge the aid of several individuals whose assistance was of inestimable value: Seymour Weingarten, executive editor for Plenum Publishing Corporation; Larry Kokkinidis and Gary Remington for their critical comments on Chapters 1, 3, and 5; Joan Drummond and Beverly Riley who patiently and competently typed successive versions of most chapters; Luigi Amorico and Luigi De Acetis for their assistance in the preliminary preparation of Chapters 4 and 7; Steve Glazier and Jill Morowski for the preparation of the indexes; Maida and Ann-Charlotte for too many things to be listed here; and Simon A. and Francesco B. in memoriam, whose endowments to us still appear frequently.

Hymie Anisman

Giorgio Bignami 


\section{Contents}

Chapter 1

Aversively Motivated Behavior as a Tool in Psychopharmacologic Analysis

Hymie Anisman

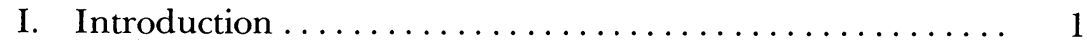

II. Theoretical Models ......................... 3

III. Components of Avoidance Behavior-Implications for Psychopharmacology $\ldots \ldots \ldots \ldots \ldots \ldots \ldots \ldots \ldots \ldots . \quad 8$

A. Associative Processes-Drive Components ........ 8

B. Associative versus Nonassociative Processes-Response Components ....................... 9

C. Stimulus-Response Interface $\ldots \ldots \ldots \ldots \ldots \ldots \ldots 11$

D. Pseudoconditioning and Anticipatory Responding .... 12

E. Deductions and Predictions ................. 13

IV. Strategies for the Assessment of Treatment Effects ...... 14

A. Discrete-Trial Active Avoidance: Task Manipulations and Multiple Testing Procedures .............. 14

B. Response Suppression .................. 21

C. Controls for Activity and Responsivity to Shock ..... 25

D. Discriminated Avoidance: Simultaneous and Successive Procedures ............................. 29

E. Sidman (Continuous) Avoidance .............. 34

F. Drugs as Aversive Stimuli .................. 36

G. Transfer Designs $\ldots \ldots \ldots \ldots \ldots \ldots \ldots \ldots \ldots \ldots$

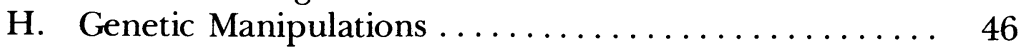

I. Cluster Analysis ........................ 50

V. General Summary ......................... 51

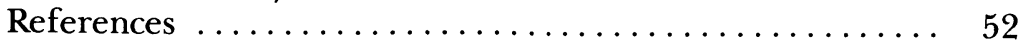


Chapter 2

Behavioral Genetics and Animal Learning

Douglas Wahlsten

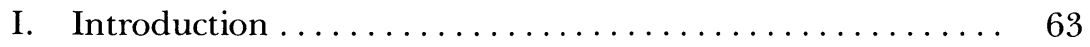

II. Basic Concepts and Methods .................... 64

A. Heredity and Genetics ..................... 64

B. Origins of Laboratory Animals .............. 65

C. Breeding Systems and Research Applications ....... 67

III. Major Research Questions ................... 74

A. General Learning Ability .................. 74

B. Dimensional versus Pairwise Variation ........... 89

C. Dissection of the Learning Process ............ 93

D. Equating Effects of Experimental Manipulations .... 98

IV. Mendelian Inheritance, Pleiotropy, and Relations between

Characters .............................. 104

A. Mendelian Inheritance $\ldots \ldots \ldots \ldots \ldots \ldots \ldots \ldots \ldots$

B. Genetic Correlation and Physiological Causation ...... 105

C. Behavioral Pleiotropy $\ldots \ldots \ldots \ldots \ldots \ldots \ldots . . \ldots 6$

D. "Trivial" Pleiotropy and Genuine Relations ........ 107

E. "Genuine" Pleiotropy and Spurious Relations ....... 109

F. A Reformulation ........................ 111

References ............................ 113

Chapter 3

Neurochemical Changes Elicited by Stress: Behavioral Correlates

Hymie Anisman

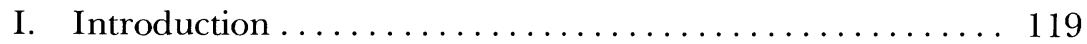

II. Effects of Acute Stress on Levels and Turnover of NE, DA,

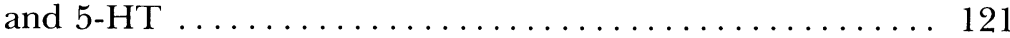

A. Electric Foot Shock ................... 121

B. Cold, Restraint, and Oscillation Stress .......... 133

C. Isolation ............................ 136

III. Stress-Induced Increases in Amine Levels ............ 137

IV. Neurochemical Change and Coping Style ........... 139

A. Escapable versus Inescapable Stress ............ 139

B. Effects of Repeated or Chronic Stress .......... 143

V. Hormonal Changes after Stress ................. 147

VI. Genetic Factors ......................... 149

A. Endogenous Differences in Neurochemical Levels .... 149

B. Stress-Induced Neurochemical Effects ........... 150

C. Stress Effects after Drug Treatments ............ 151 
VII. Stress-Induced Neurochemical Changes: Implications for Avoidance Behavior ....................... 152

VIII. Implications for Human Behavior .............. 154

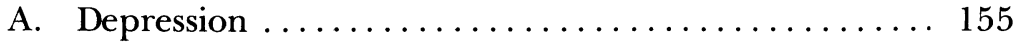

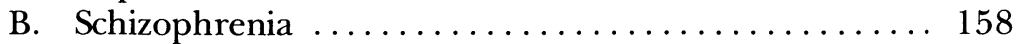

IX. Overview ............................... 159

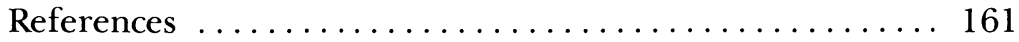

Chapter 4

Cholinergic Mechanisms and Aversively Motivated Behaviors

Giorgio Bignami and Hanna Michalek

I. Introduction ............................. 173

II. Selected Neurochemical Aspects of Cholinergic Drug Action 176

A. Characterization of Cholinergic Receptors ......... 176

B. Effects of Cholinergic Agonists .............. 182

C. Effects of Cholinergic Antagonists ............. 186

D. Some Effects of Other Agents .............. 189

III. Behavioral Effects of Muscarinic Agonists and Antagonists 192

A. Activity, Exploration, Habituation, and Sensory

Reinforcement .......................... 192

B. Responses to Aversive Stimuli ................ 194

C. Fear Conditioning $\ldots \ldots \ldots \ldots \ldots \ldots \ldots \ldots \ldots \ldots$

D. Passive Avoidance ......................... 199

E. Active Avoidance ......................... 205

IV. Sites of Drug Action......................... 221

A. Neuropsychological Investigations ............ 221

B. Selected Anatomical and Physiological Data on Cholinergic Mechanisms and Pathways ........... 225

C. Tentative Conclusions on Muscarinic Mechanisms .... 228

V. Nicotinic Stimulation and Blockade ............ 229

A. Nonmonotonic Response Changes after Nicotine .... 229

B. Possible Mechanisms of Nicotine Action: Nicotinic

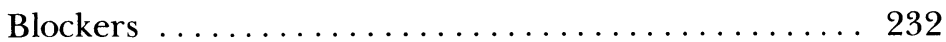

VI. General Conclusions ....................... 234

References ............................ 235

Chapter 5

Monoamines and Aversively Motivated Behaviors

David A. V. Peters, Hymie Anisman, and Bruce A. Pappas

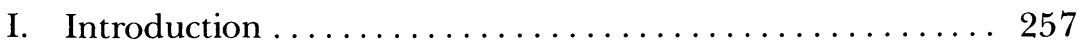

II. Neuropharmacology of the Monoamines .......... 258

A. General Characteristics .................. 258 
B. Monoamine Pathways $\ldots \ldots \ldots \ldots \ldots \ldots \ldots \ldots . \ldots \ldots$

C. Biosynthesis of the Catecholamines ............ 264

D. Biosynthesis of Serotonin ................ 267

E. The Metabolic Inactivation of the Monoamines ...... 269

III. Some Aspects of the Neuropharmacology of the Monamines 271

A. Monoamine Synthesis Inhibitors ............. 271

B. Cytotoxic Agents ....................... 274

C. Drugs That Increase Monoamine Levels at Receptors ........................ 278

D. Drugs That Affect Monoamine Storage ......... 280

E. Serotonin Antagonists ................... 283

IV. Catecholaminergic Mechanisms and Nonassociative Behavioral Change ......................... 284

A. Catecholamine Involvement in Motor Activity ....... 284

V. Catecholaminergic Mechanisms and Aversively Motivated Behaviors ................................ 289

A. Chemical Lesions ....................... 289

B. Receptor Blockade and Synthesis Inhibition ....... 298

C. Catecholamine Stimulants ................. 301

D. Memory Interpretations Concerning Behavioral

Changes Induced by Catecholaminergic Agents .... . 305

VI. Serotonergic Mechanisms and Aversively Motivated Behaviors ............................. 308

A. Chemical Lesions, Synthesis Inhibition, and Administration of Precursors . . . . . . . . . . . . . . . 308

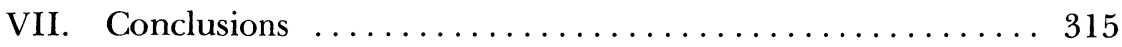

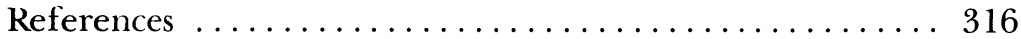

Chapter 6

\section{Hallucinogens}

Alvin K. Swonger and Richard H. Rech

I. Introduction ......................... 345

II. The General Pharmacology of Hallucinogens $\ldots \ldots \ldots \ldots 346$

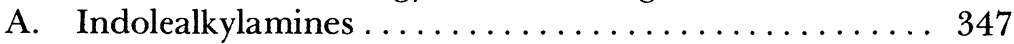

B. Phenethylamines ..................... 348

C. Miscellaneous Anticholinergics $\ldots \ldots \ldots \ldots \ldots \ldots \ldots 348$

D. Phenylcyclohexyl Derivatives .............. 350

III. Effects of Hallucinogens on Animal Behavior ......... 350

A. Effects on Habituation, Spontaneous Alternation, and Locomotor Activity .................... 351 
B. Active Avoidance ..................... 351

C. Passive Avoidance and Go-No-Go Paradigms ...... 356

D. Effects on Appetitive Operant Responding ....... 356

E. Conditioned Aversion .................... 357

IV. Current Models and Hypotheses for the Effects of Hallucinogens ........................... 357

A. Indole and Phenethylamine Hallucinogens ....... 358

B. Cannabis ............................. 369

V. Relevance to Human Effects ................. 372

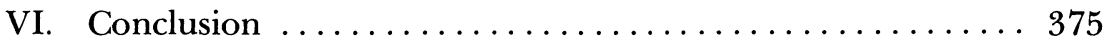

References ........................... 375

Chapter 7

Effects of Neuroleptics, Ethanol, Hypnotic-Sedatives, Tranquilizers, Narcotics, and Minor Stimulants in Aversive Paradigms

Giorgio Bignami

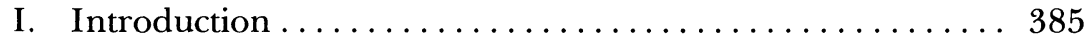

II. Neuroleptics (Major Tranquilizers) ............. 387

A. Antiavoidance Action .................. 388

B. Unlikely or Insufficient Explanations of the Antiavoidance Action: Antinociception-Associative and Motivational Deficits ................. 392

C. Sensory versus Motor Explanations of the Neuroleptic Syndrome .......................... 395

D. Miscellaneous Problems ..................... 399

III. Ethanol, Hypnotic-Sedatives, and Minor Tranquilizers . . . 402

A. The Anticonflict or Antipunishment Action ........ 403

B. Effects on Other Aversively Motivated Behaviors ..... 409

C. Hypotheses on the Mechanisms Underlying the Anticonflict Action ....................... 420

IV. Narcotic Agonists and Antagonists ................ 423

A. Punishment Suppression ................. 424

B. Active Avoidance ........................ 424

V. Miscellaneous Stimulants ..................... 427

A. Xanthines (Caffeine and Related Agents) ......... 428

B. Antidepressants ........................... 429

C. Magnesium Pemoline ................... 431

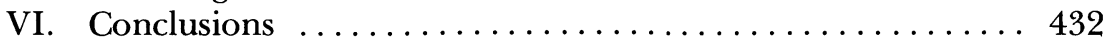

References ........................... 433 
Chapter 8

Stimulus Attributes of Drugs

Herbert Barry, III

I. Drugs as Unconditioned Punishing Stimuli . . . . . . . . 456

A. Toxic Drug Effects . . . . . . . . . . . . . . 457

B. Tolerance and Withdrawal Illness ... . . . . . . 459

C. Conditioned Stimulus for Aversive Drug Effects ..... 461

II. Drugs as Unconditioned Reinforcing Stimuli . . . . . . . . 463

A. Drug Self-Administration to Relieve Aversive

Conditions ..................... 463

B. Chronic Drug Intake . . . . . . . . . . . . 465

C. Conditioned Stimulus for Drug-Mediated Relief . . . . 466

III. Drugs as Conditioned Stimuli ... . . . . . . . . . . 467

A. Variations in Discriminative Responses . . . . . . . . 467

B. General Attributes of Discriminative Drug Effects . . . 475

C. State-Dependent Effects and Amnesia .......... . . 477

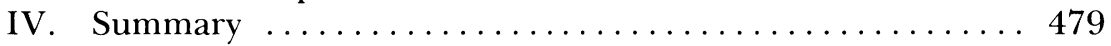

References ...................... 480

Chapter 9

A Comparative Neurochemical, Pharmacological, and Functional Analysis of Aversively Motivated Behaviors: Caveats and General Considerations

Hymie Anisman and Giorgio Bignami

I. Theoretical Frameworks for Aversively Motivated Behaviors 488

A. General Considerations ... . . . . . . . . . . . . 488

B. Methodological Issues in Pharmacological and

Neuropsychological Analysis ................ 489

II. Role of Neurochemical Activity in Aversive Situations . . . . 494

A. Acetylcholine ... . . . . . . . . . . . . . . . 495

B. Dopamine and Norepinephrine ............ 496

C. Serotonin ............................. 497

D. Neurotransmitter Interactions . . . . . . . . . . . 497

III. Comparative Analysis of Selected Drug-Induced Syndromes 499

IV. Relevance of Research on Infrahuman Subjects to Human

Psychopharmacology ................... 505

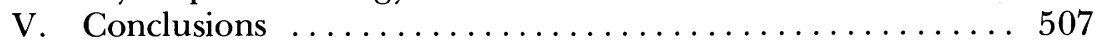

References ...................... 508

Author Index . . . . . . . . . . . . . . . . . . . . . . 513

Subject Index . . . . . . . . . . . . . . . . . 537 